but above all of the Chinese way of thinking and of handling matters.

This failure to understand Chinese affairs has nothing to do with oriental inscrutability. We are about as inscrutable to them as they are to us, which doesn't make things easier. Unfortunately, Westerners tend to forget that China is not just another country but another civilization which has grown up for four thousand years parallel with our own and essentially independent of it. Any attempt to understand the Chinese must fail unless we are willing to learn something about their world.

Hardly anyone is better qualified to teach us than Dr Joseph Needham, whose long years of study in China have ranged far beyond his chosen field of Chinese science. For the better part of two thousand years, China has been governed by a civil service of scholars, and in his latest book the author talks about the heritage of the country as a scholar and poet very much in the traditional Chinese manncr. Within the Four Seas is a collection of twenty-two essays, addresses and poems written and published separately between 1942 and 1967 . They cover a wide range of subjects from distant historical events to the Vietnam war and from religion to science. Nevertheless they are held together by Needham's sensitive style and his profound analysis.

Of the essays, that on "The Past in China's Present" is the longest and runs for almost sixty pages. In it, the author presents a beautifully clear and concise account of the essential developments of Chinese society on which its present aspects are founded. In particular, the immensely important role of the mandarinate in the shaping of China's history is explained. In its own interest the civil scrvice of scholar officials prevented the growth of capitalism, and its central organization inhibited the rise of eity states which might have been the cradle of a scientific renaissance. We also learn about the part played by the famous secret societies which have flourished throughout China's history. They were the only means of forcing a change of government in a country the basic concepts of administration of which left no room for political parties.

These are just a few of the issues dealt with in one of the essays. They are certainly worth re-reading, and not only because they provide valuable factual information. Through his measured and scholarly approach, and especially by including the poems, the author has succeeded in conveying, almost imperceptibly, somothing even more important: a subtle glimpse of the spirit of China.

Those who expect startling political disclosures or the latest account of the cultural revolution will be disappointed. The cultural revolution is not even mentioned and the chronological table given at the end of the book ends in 1949. Even so, the book can be warmly recommended to everybody who is interested in China, and that should include the columnists all over the Western world who have made contemporary China their subject. It will go a long way towards teaching the "China watchers" wisdom.

K. Mendelssohn

\section{STRUCTURE OF STARS}

Principles of Stellar Structure

By John P. Cox, in collaboration with R. Thomas Giuli. Vol. 1: Physical Principles. Pp. $\mathrm{xx}+1-568.360 s$. Vol. 2: Applications to Stars. Pp. 569-I327. 420s. (Gordon and Breach: London, November 1968.) 750s for the pair.

THE subject of stellar structure (including stellar evolution) is one which has developed rapidly in the past decade. While the fundamental principles of stellar structure and evolution were laid down in the $1930 \mathrm{~s}$, the development of numerical techniques of the 1950s was required before a broad view of the subject could be obtained. The advent of high speed digital computing added immeasurably to this broad vicw. Current research is now dealing (by comparison with the preceding studies) with more minor aspects of stellar evolution. 'These problems require immense computing resources and expertise, and their elucidation will not only yield a great deal in connexion with stellar structure but may also have important repercussions for our understanding of cosmology.

Many of the standard texts on stellar structure relate to the theory of stellar structure as it was in the late $1950 \mathrm{~s}$ and early $1960 \mathrm{~s}$. It is therefore particularly exciting to see a text on stellar structure which includes so much modern work. This book is very comprehensive and provides a first class insight into modern views of stcllar structure. The volumes are arranged so that the first volume treats the basic physics which is required in stellar structure. Volume one is concerned with establishing a good understanding of thermal equilibrium, radiation theory including its absorption by stellar material, thermodynamics, convection, and sources of stellar energy. Many of these topics are absent from modern courses in physics and these problems are discussed in the volume in a workmanlike and thorough way. Volume two is concerned with the application of these physical principles to stars. This volume opens with the VogtRussell theorem, some of the early simple stellar models and $\mathrm{a}$ brief treatment of stellar atmospheres before proceeding to consider more modern work. It is particularly interesting to note a chapter on semi-degenerate equations of state in viow of the importance of such configurations for stellar cores. White dwarfs and pulsating stars are also discussed and there is an extensive section on stellar evolution. Volume two also has an interesting updating supplement-a useful idea in a book which necessarily needed so long to prepare.

There is a relaxed style of writing in both volumes, and volume one in particular benefits from this. I recommend this volume unreservedly to a wide readership from undergraduate students (to whom it is well suited except in one important respect) to research workers, and Cox has done astrophysics a service. Volume two, on the other hand, suffers a little from the relaxed style-it often tantalizes the reader with what might have been. Of course, in a subject such as this, separate volumes eould be written on each of the chapter headings and one wonders what has been gained by going just a little beyond more compact treatments if one considers only undergraduate studies. I feel many undergraduates confronted with volume two would find the trees obstructing the wood in many places and might abandon the book before they realized what a useful guide to the modern literature it was. Volume two is really for postgraduate students and research workers. While I feel this volume is not so sucecssful as volume one, both are a remarkable tribute to the authors and an outstanding contribution to the reference works of current astrophysics. I feel these volumes will remain a standard text for many years.

While paying compliments to authors it is always nice, however, to pay compliments to publishers. In this instance, while noting that these books are well produced, I am compelled to remark that the price is ridiculous (to be at one's most charitable). Clearly the publishers only wish to interest the 500 or so astronomical libraries who like to keep fully up to date. In these times, many libraries will buy only one copy where at least a duplicate set would be more generally useful, and many smaller institutions just will not use their library grant in this cavalier way. Most individuals (particularly postgraduato students whom it would most benefit) just will not buy it. It is therefore a thousand pities that the book may only become a work of reference and not a useful and well thumbed text. D. MCNALLY 